\title{
Estimating the tolerance of brachial plexus to hypofractionated stereotactic body radiotherapy: a modelling-based approach from clinical experience.
}

\author{
Irina Kapitanova \\ Mount Sinai St. Luke's Hospital \\ Sharmi Biswas \\ Weill Cornell Medicine \\ Sabrina Divekar \\ Tel Aviv University
}

Ebildow. thesanateratditional works at: https://jdc.jefferson.edu/radoncfp

O-isinger Cancer Institute

Part of the Oncology Commons, and the Radiation Medicine Commons

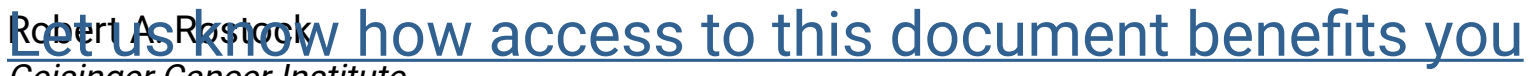
Geisinger Cancer Institute

\section{Recommended Citation}

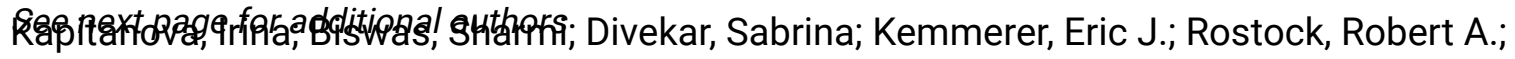

Forster, Kenneth M; Grimm, Rachel J.; Scofield, Carla J; Grimm, Jimm; Emami, Bahman; and

Mahadevan, Anand, "Estimating the tolerance of brachial plexus to hypofractionated

stereotactic body radiotherapy: a modelling-based approach from clinical experience." (2021).

Department of Radiation Oncology Faculty Papers. Paper 155.

https://jdc.jefferson.edu/radoncfp/155

This Article is brought to you for free and open access by the Jefferson Digital Commons. The Jefferson Digital Commons is a service of Thomas Jefferson University's Center for Teaching and Learning (CTL). The Commons is a showcase for Jefferson books and journals, peer-reviewed scholarly publications, unique historical collections from the University archives, and teaching tools. The Jefferson Digital Commons allows researchers and interested readers anywhere in the world to learn about and keep up to date with Jefferson scholarship. This article has been accepted for inclusion in Department of Radiation Oncology Faculty Papers by an authorized administrator of the Jefferson Digital Commons. For more information, please contact: JeffersonDigitalCommons@jefferson.edu. 


\section{Authors}

Irina Kapitanova, Sharmi Biswas, Sabrina Divekar, Eric J. Kemmerer, Robert A. Rostock, Kenneth M Forster, Rachel J. Grimm, Carla J Scofield, Jimm Grimm, Bahman Emami, and Anand Mahadevan 


\title{
Estimating the tolerance of brachial plexus to hypofractionated stereotactic body radiotherapy: a modelling-based approach from clinical experience
}

Irina Kapitanova', Sharmi Biswas², Sabrina Divekar ${ }^{3}$, Eric J. Kemmerer ${ }^{4}$, Robert A. Rostock ${ }^{4}, K^{2}$ Kenneth M. Forster ${ }^{4}$, Rachel J. Grimm ${ }^{5}$, Carla J. Scofield ${ }^{4}$, Jimm Grimm ${ }^{4,6^{*}} \mathbb{0}$, Bahman Emami ${ }^{7}$ and Anand Mahadevan ${ }^{4}$

\begin{abstract}
Background: Brachial plexopathy is a potentially serious complication from stereotactic body radiation therapy (SBRT) that has not been widely studied. Therefore, we compared datasets from two different institutions and generated a brachial plexus dose-response model, to quantify what dose constraints would be needed to minimize the effect on normal tissue while still enabling potent therapy for the tumor.
\end{abstract}

Methods: Two published SBRT datasets were pooled and modeled from patients at Indiana University and the Richard L. Roudebush Veterans Administration Medical Center from 1998 to 2007, as well as the Karolinska Institute from 2008 to 2013. All patients in both studies were treated with SBRT for apically located lung tumors localized superior to the aortic arch. Toxicities were graded according to Common Terminology Criteria for Adverse Events, and a probit dose response model was created with maximum likelihood parameter fitting.

Results: This analysis includes a total of 89 brachial plexus maximum point dose (Dmax) values from both institutions. Among the 14 patients who developed brachial plexopathy, the most common complications were grade 2, comprising 7 patients. The median follow-up was 30 months (range 6.1-72.2) in the Karolinska dataset, and the Indiana dataset had a median of 13 months (range 1-71). Both studies had a median range of 3 fractions, but in the Indiana dataset, 9 patients were treated in 4 fractions, and the paper did not differentiate between the two, so our analysis is considered to be in 3-4 fractions, one of the main limitations. The probit model showed that the risk of brachial plexopathy with Dmax of 26 Gy in 3-4 fractions is 10\%, and 50\% with Dmax of 70 Gy in 3-4 fractions.

Conclusions: This analysis is only a preliminary result because more details are needed as well as additional comprehensive datasets from a much broader cross-section of clinical practices. When more institutions join the QUANTEC and HyTEC methodology of reporting sufficient details to enable data pooling, our field will finally reach an improved understanding of human dose tolerance.

*Correspondence: JimmGrimmJr@yahoo.com

${ }^{4}$ Department of Radiation Oncology, Geisinger Cancer Institute, $100 \mathrm{~N}$ Academy Ave, Danville, PA 17822, USA

Full list of author information is available at the end of the article

\section{Background}

Stereotactic body radiation therapy (SBRT) is a treatment option increasingly used for patients with lung cancer, including apical lung tumors, who are not surgical candidates. The main objective of the treatment is to provide the most effective SBRT dose on the tumor original author(s) and the source, provide a link to the Creative Commons licence, and indicate if changes were made. The images or other third party material in this article are included in the article's Creative Commons licence, unless indicated otherwise in a credit line to the material. If material is not included in the article's Creative Commons licence and your intended use is not permitted by statutory regulation or exceeds the permitted use, you will need to obtain permission directly from the copyright holder. To view a copy of this licence, visit http://creativecommons.org/licenses/by/4.0/. The Creative Commons Public Domain Dedication waiver (http://creativeco mmons.org/publicdomain/zero/1.0/) applies to the data made available in this article, unless otherwise stated in a credit line to the data. 
with minimal effect on normal tissue while avoiding post-radiation complications. Based on the tumor location (proximal of the brachial plexus), tumor size, dose, and numerous other factors, a potentially severe adverse effect after SBRT is radiation induced brachial plexopathy (RIBP) [1, 2]. Onset of RIBP symptoms may occur from months to years after the radiotherapy [3]. Brachial plexopathy, as defined in the Common Terminology Criteria for Adverse Events (CTCAE) v.5 [4], may include muscle weaknesses of the upper limbs, neuropathic pain, limitation of movement, paresthesia, and wasting. Understanding the tradeoffs between the benefits and risks in SBRT dose and fractionation can provide clarity by considering the range of severity in symptoms, from asymptomatic to full loss of movement of the upper extremity.

In 1991, the Emami paper [5] recommended a 5\% risk in 5-year tolerance dose (TD 5/5) on the entire brachial plexus to be $60 \mathrm{~Gy}$ in conventional fractionation, based on expert opinion and on dose-response models [6]. Just 3 years later, the first clinical SBRT paper [7] included a dose-response model [8] to guide clinical practice, and a recent dose-response model for brachial plexus has been published [2] by the same institution. After a quarter of a century of SBRT practice, other studies validating these models are lacking and are needed to definitively determine tolerance of brachial plexus to SBRT. North American clinical trials for stereotactic ablative body radiotherapy (SABR) began at Indiana University [9], and the brachial plexus dose and toxicity outcome for each patient in a cohort was published [1]. The datasets from Indiana University and Karolinska Institute were pooled in the current study and analyzed as recommended by QUANTEC methodology [10, 11]. If this was standard practice in radiation oncology, then our understanding of human dose tolerance of various normal tissues to radiation would be vastly improved. Unfortunately, these examples are the extreme rarity, to the degree that, although a PubMed search of (SBRT OR SABR) AND (spinal cord) returns more than 250 papers, the High Dose per Fraction, Hypofractionated Treatment Effects in the Clinic (HyTEC) [12] effort was only able to find 3 papers that provided full datasets with critical structure dose and toxicity outcome per patient for spinal cord, which only represents about $1 \%$ of the published literature.

If detailed reporting of the spinal cord is so rare, even though it is among the most important critical structures in the body, it will be even harder to accumulate sufficient data for other organs. Therefore, is it possible to create comprehensive Emami-style dose tolerance limits [5] for intricate structures such as brachial plexus? The goal of the dose volume histogram (DVH) Risk Map [13] is to provide a modernized graphical view of Emami-style unified low- and high-risk limits, along with a numerical summary of the constraints and estimates of associated risk. The aim of this paper is to summarize initial steps towards creation of the DVH Risk Map for the brachial plexus as an impetus to improve data reporting across published literature for better understanding of tolerance levels.

\section{Methods}

To identify brachial plexus dose tolerance after SBRT based on dose-response models of clinical outcomes data, the following 6 elements are needed: (1) dose to the brachial plexus, (2) fractionation, (3) volume, (4) endpoint, (5) follow-up time, and (6) incidence of the endpoint occurring within the follow-up time [13]. These 6 items are needed per patient, or at least in enough detail to stratify data into small groups of patients with similar characteristics. A PubMed search for (brachial plexus) AND (stereotactic OR SABR OR SBRT) was performed, and 52 papers were found as of July 2020, but only two of the studies came close to providing the needed information for all patients in a study.

The two datasets were comprised of patients treated (1) at Indiana University and the Richard Roudebush Veterans Administration Medical Center from 1998 to 2007 [1] as well as (2) the Karolinska Institute from 2008 to 2013 [2]. All patients in both studies were treated for apically located lung tumors localized superior to the aortic arch. A total of 89 patients (with 93 lesions) from both institutes received SBRT and were included in this analysis.

Physical dose without any biological conversions was used in the graph of presented brachial plexus maximum doses in the Indiana dataset, and the linear quadratic (LQ) model $[14,15]$ as well as the universal survival curve (USC) [16] were used to assess the data. In the Karolinska dataset, dose-response models were created using both the LQ and USC models. The probit dose-response model [17] was used in the Lindberg et al. [2] study, so this model was also used in our pooled analysis for consistency. Brachial plexus maximum point dose (Dmax) values were digitized from the source graphs $[1,2]$ with the DVH Evaluator software [13], which then was used to perform maximum likelihood parameter fitting [18] to determine the values for the probit model [17], and confidence intervals were constructed using the profile likelihood method [19, 20].

All clinical data were collected from the patient records and graded using the Common Terminology Criteria for Adverse Events (CTCAE). Only toxicities of Grade 2 and greater in both studies were scored as complications. Indiana University used CTCAE version 3.0 [21] with scoring of grade 1-4 while Karolinska used CTCAE version 4.0 [22]. CTCAE version 3.0 focused more on 
the symptoms affecting activities of daily living while version 4 stressed the severity of the symptoms. For the purpose of inclusion, we have also included the Modified Late Effects Normal Tissue-Subjective Objective Management Analytic (LENT-SOMA) scale [23, 24] to compare the brachial plexus adverse effects. The details of the grading of toxicity are shown in Table 1 . The following variables were considered in the comparison of toxicity rates: gender, age, histology, number and size of tumors, dose of SBRT, number of fractions, and time to brachial plexopathy from SBRT. The Fisher Exact Test was used to assess significance among individuals with toxicity and those without toxicity $[25,26]$.

\section{Results}

Patient characteristics, SBRT doses, and grading of radiation induced brachial plexopathy are compared in Table 2 for both studies. The median patient age was 72 and 73

Table 1 Endpoint definitions: brachial plexus toxicity grading scales

\begin{tabular}{|c|c|c|c|}
\hline & CTCAE Version 3.0 [21] & CTCAE Version 4.0 [22] & Modified LENT-SOMA scale [23] \\
\hline Grade 1 & Asymptomatic brachial plexopathy & Asymptomatic effects & $\begin{array}{l}\text { Mild sensory deficits, no pain, no treatment } \\
\text { required }\end{array}$ \\
\hline Grade 2 & $\begin{array}{l}\text { Symptomatic brachial plexopathy without inter- } \\
\text { fering with activities of daily living (ADL) }\end{array}$ & Moderate symptoms limiting ADL & $\begin{array}{l}\text { Moderate sensory deficits, tolerable pain, mild } \\
\text { arm weakness }\end{array}$ \\
\hline Grade 3 & $\begin{array}{l}\text { Symptomatic brachial plexopathy and interfer- } \\
\text { ing with ADL }\end{array}$ & Severe symptoms limiting self care ADL & $\begin{array}{l}\text { Continuous paresthesia, with incomplete paresis, } \\
\text { pain medication required }\end{array}$ \\
\hline Grade 4 & Disabling brachial plexopathy & $\mathrm{N} / \mathrm{A}$ & $\begin{array}{l}\text { Complete paresis, excruciating pain, muscle } \\
\text { atrophy, regular pain medication required }\end{array}$ \\
\hline
\end{tabular}

CTCAE common terminology criteria for adverse events, LENT late effects normal tissues, SOMA subjective, objective, management, analytic, $A D L$ activities of daily living

Table 2 Apical lesion patient characteristics

\begin{tabular}{|c|c|c|c|}
\hline & Indiana University & Karolinska University & Total \\
\hline Number of patients & 37 & 52 & 89 \\
\hline \multicolumn{4}{|l|}{ Gender } \\
\hline Male & 21 & 23 & 44 \\
\hline Female & 16 & 29 & 45 \\
\hline Age at treatment, median (range) & $73(57-81)$ & $72(35-88)$ & \\
\hline Number of tumors & 37 & 56 & 93 \\
\hline Primary lung cancer (NSCLC) & 37 & $30^{\mathrm{a}}$ & 67 \\
\hline Metastases & 0 & 22 & 22 \\
\hline \multicolumn{4}{|l|}{ Tumors } \\
\hline Right & 21 & 28 & 49 \\
\hline Left & 16 & 28 & 44 \\
\hline Volume cc, median (range) & GTV $13(1-113)$ & CTV $9.1(0.10-74.5)$ & \\
\hline Follow-up months, median (range) & $13(1-71)$ & $30(6.1-72.2)$ & \\
\hline Total treatment dose (Gy), median (range) & $57(30-72)$ & $\begin{array}{l}\text { Median } 45 \text { Gy in } 3 \mathrm{fx} \\
\text { BED10 Range: } 95-138 \mathrm{~Gy}\end{array}$ & \\
\hline Median dose per fraction (Gy) (range) & $19(10-24)$ & $15(6-17)$ & \\
\hline Median number of fractions (range) & $3(3-4)$ & $3(3-10)$ & \\
\hline \multicolumn{4}{|l|}{ Number of patients with brachial plexopathy } \\
\hline Total & 7 & 7 & 14 \\
\hline Grade 2 & 4 & 3 & 7 \\
\hline Grade 3 & 2 & 4 & 6 \\
\hline Grade 4 & 1 & 0 & 1 \\
\hline $\begin{array}{l}\text { Brachial plexopathy development in months post-SBRT, } \\
\text { median (range) }\end{array}$ & $7(6-23)$ & $5.8(0.7-13)$ & \\
\hline
\end{tabular}

NSCLC non-small cell lung cancer, GTV gross tumor volume, CTV clinical tumor volume, $f x$ fractions; $B E D 10$ biological effective dose with a/ $\beta=10 \mathrm{~Gy}$

a One patient with metastasis later on 
for Karolinska University and Indiana University, respectively. 93 tumors were treated in total with 22 patients having metastases.

\section{Dose, fractionation, and volume of the brachial plexus}

At Indiana University, the median prescribed treatment dose was 57 Gy in 3-4 fractions and the maximum brachial plexus dose ranged from 6 to 83 Gy (median, 26 Gy). The Indiana University dataset had 37 brachial plexus Dmax values (for 36 patients) that were all included in the model. The paper did not report which patients received 3 or 4 fractions, or volume information, and these are the main limitations of the study [1]. Both published datasets $[1,2]$ used biological conversions with $\alpha / \beta=3 \mathrm{~Gy}$, thus the biological effective dose is denoted as $\mathrm{BED}_{3}$. According to the linear quadratic model [14, $15]$, the 2 Gy per day equivalent EQD2 $=60$ Gy Emami brachial plexus limit [5] corresponds to $\mathrm{BED}_{3}=100 \mathrm{~Gy}$. In 3 fractions, LQ equates this to $26 \mathrm{~Gy}$, which was equal to the median brachial plexus Dmax of the 37 cases, and this was initially used as a cutoff point of risk analysis, finding the two-year Kaplan-Meier risk of $46 \%$ vs $8 \%$ above and below this cutoff [1].

The Karolinska group used 45 Gy in 3 fractions for $80 \%$ of the cases, therefore that also was the median prescription. One patient was treated with 60 Gy in 10 fractions, six were treated with 56 Gy in 8 fractions, and the rest were in 3-5 fractions. The authors performed analysis with both USC and LQ models and found no major difference between the two for their data, so presented the data in terms of $\mathrm{BED}_{3}$ with the $\mathrm{LQ}$ model. Brachial plexus Dmax ranged from $\mathrm{BED}_{3}=0.10-524 \mathrm{~Gy}$, which we converted to 3 -fraction equivalent dose since the median number of fractions in both studies was 3 . The Karolinska dataset presented model parameters for Dmax, in addition to dose to hottest X cc (Dx) for D0.1cc, D1cc and D3cc, but the group from Indiana University only reported on Dmax. Therefore, the pooled model has no volume information, and consists of maximum point doses only.

\section{Endpoint, Follow-up time, and estimated risk of the endpoint occurring within the follow-up time}

Follow-up was longer in Karolinska with median 30 months (range 6.1-72.2) while Indiana had a median of 13 months (range 1-71). Among the 89 patients included in both studies, 14 of them developed CTCAE grade 2 or higher RIBP, acknowledging the differences among the endpoint definitions in Table 1. Among the 14 , the most common complications were grade 2 , comprising 7 patients. Only 1 patient from Indiana University was recorded with grade 4 disabling RIBP described as shoulder ache progressing to paresthesia and further worsening to arm and hand wasting. This case corresponded to brachial plexus Dmax of 76 Gy. One patient from Karolinska also noted signs of RIBP 13 months post SBRT further progressing to total paralysis of the arm, but was scored as grade 3 since CTCAE 4.0 is without grade 4 RIBP. Therefore, the LENT-SOMA scale is a useful point of comparison in this regard as shown in Table 1, because it does include a definition of grade 4 .

It is also important to note that in the Karolinska study, 13 patients underwent additional radiotherapy to the lung ipsilateral to the tumor site that is not included in the model in Fig. 1. Out of the 13, 10 of the patients had very low additional brachial plexus dose, $D_{\max }$ $\mathrm{BED}_{3} \leq 3.1 \mathrm{~Gy}$. The remaining 3 had a prior conventional dose of $\mathrm{D}_{\max } \mathrm{BED}_{3}=90-123$ Gy with only 1 patient from this subset developing RIBP. Therefore, for the Karolinska study, 6 out of 7 patients developed RIBP strictly only from the SBRT.

\section{Dose-response model and DVH Risk Map}

Given the approximation of the 6 elements needed for a dose-response model [13], and considering their limitations, caveats, and confounding factors as enumerated above and described in the discussion, a pooled doseresponse model was created. According to the fitted probit model [17-20], the dose corresponding to $50 \%$ risk of complications was 70.2 Gy (95\% CI 55-116 Gy), and the slope parameter at this dose was 0.49 (95\% CI 0.35-0.74).

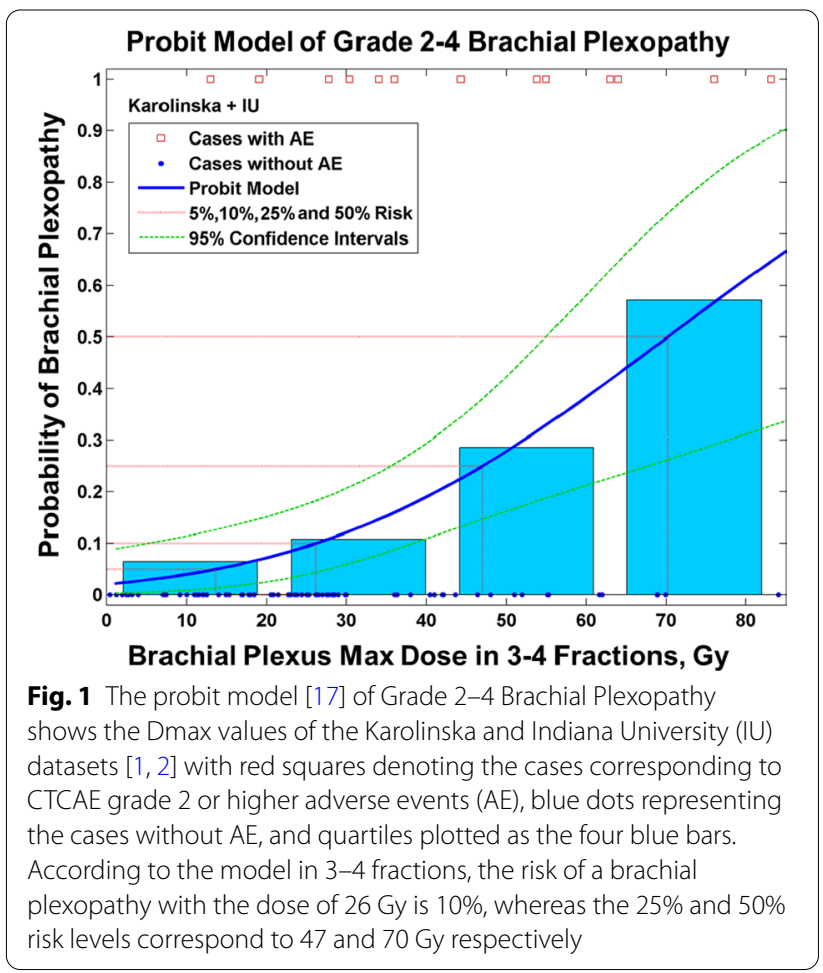


The probit model and 95\% confidence intervals are depicted in Fig. 1 [17-20]. Significance was assessed via the Fisher Exact Test $[25,26]$ split at the median dose of the Indiana dataset (Dmax $=26 \mathrm{~Gy})$, and at the median dose of the combined dataset $(D \max =27$ Gy), yielding p-values of 0.01 and 0.0035 , respectively. The $5 \%, 10 \%$, and $25 \%$ risk levels were $13.7,26$, and 47 Gy, respectively, in 3-4 fractions. Appendix Fig. 5 shows that for this dataset, probit and logistic models are within $\pm 1.6 \%$ of their average, up to $60 \mathrm{~Gy}$ in 3-4 fractions, and diverge from each other above this dose where the data is very sparse.

The connection between dose/volume, fractionation, and incidence of complications for the endpoint of grade 2 or higher brachial plexopathy is summarized in the form of a DVH Risk Map [13] in Fig. 2. This map includes a graph of published dose constraints in the upper portion of the figure, as well as a numerical summary of low- and high-risk constraints in the lower portion of the figure, with the resultant estimates of risk from the pooled model from Fig. 1. Appendix Fig. 4 shows how the
$5 \%$ and 50\% risk levels at 5 years (TD 5/5 and TD 50/5) in the Emami paper [5] were obtained from expert opinion and models in the Burman paper [6]. Similarly, risk levels in the DVH Risk Map in Fig. 2 are interpolated from the dose-response model of Fig. 1. A more complete description of the DVH Risk Map may be found for several other organs-at-risk in the literature [27-29].

The DVH Risk Map in Fig. 2 shows the number of fractions on the $\mathrm{x}$-axis and the raw total physical dose without any BED conversion on the $y$-axis. Each of the five panels specifies a dose/volume metric including dose for the $50 \%$ and $10 \%$ volumes, as well as D3cc, D1cc, and Dmax. Published dose constraints from Appendix Table 3 are plotted as blue diamond marks on the map (Fig. 2). These constraints were partitioned into lowand high-risk categories from among the more established limits, represented as the circled selected limits with labels. The red $\mathrm{X}$ represents the dose at which a published Adverse Event (AE) occurred, as may be seen in Appendix Table 3. For visualization, a trendline of

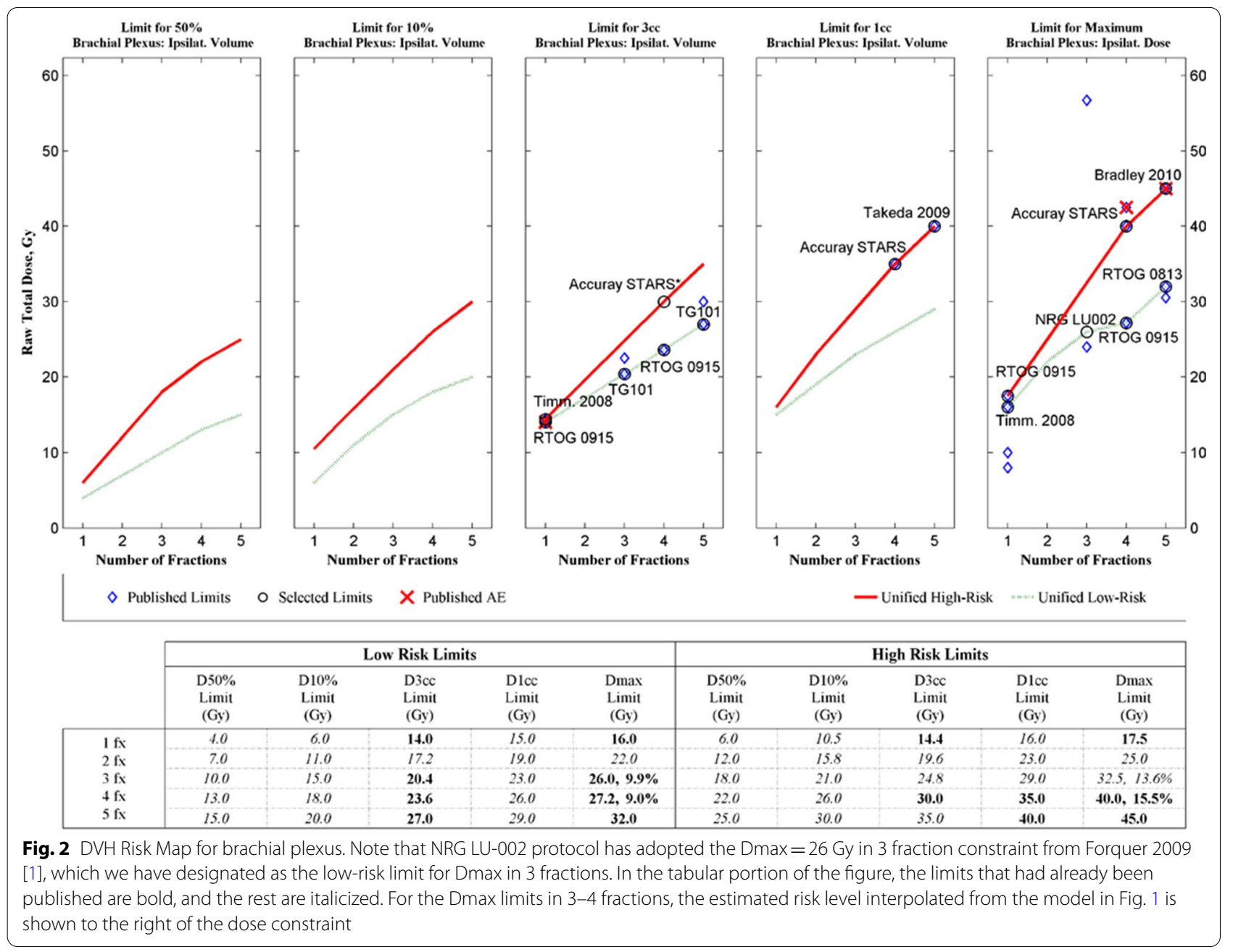


low- and high-risk are drawn as the dashed green and solid red lines in this map. Although the partitioning is somewhat arbitrary, this is approximately analogous to the TD5/5 and TD 50/5 Emami limits for conventional fractionation, but now customized to the published limits in a more useful clinical range of practice. Based on the pooled dataset, as may be seen from the tabular portion of Fig. 2, the low-risk trend of brachial plexus Dmax in $3-4$ fractions is about $10 \%$ risk and the high-risk trend is about $15 \%$ risk.

\section{Discussion}

Bias and uncertainty can result from single institution non-randomized heterogeneous mixtures of patients with varying follow-up times and unknown censoring of competing risks. Throughout the past quarter of a century, over a million patients have been treated with radiosurgery on Gamma Knife alone [30], over a million more patients have been treated with SBRT on CyberKnife alone [31], and countless more have been treated on stereotactically capable linear accelerators. No excuse remains for there to be only two limited published datasets for an important critical structure like the brachial plexus. It is imperative that the field of radiation oncology collects data more rigorously as highlighted by the lessons of QUANTEC $[10,11]$ and as continues to be emphasized by all the HyTEC papers [12, 32]. In the meantime, it is important to glean as much information as possible from the sparse datasets that do exist, and to pool them into increasingly larger datasets [10]. A full deidentified database of 197 patients with dosimetric information and outcome for each patient was published more than 100 years ago [33], showing that it is possible to accomplish this without sophisticated algorithms (Fig. 3). One of the first dose-response models was created more than 90 years ago from clinical data by hand on graph paper [34], even before the first electronic computer was invented. With modern automated algorithms, there is no excuse to not save and analyze the data in properly designed studies with actuarial outcomes at specific time points in multiple institutions with large cohorts of data. The dose-tolerance numbers for conventional fractionation from the Emami paper were based on expert opinion over 30 years ago, in terms of the radiation dose limits for

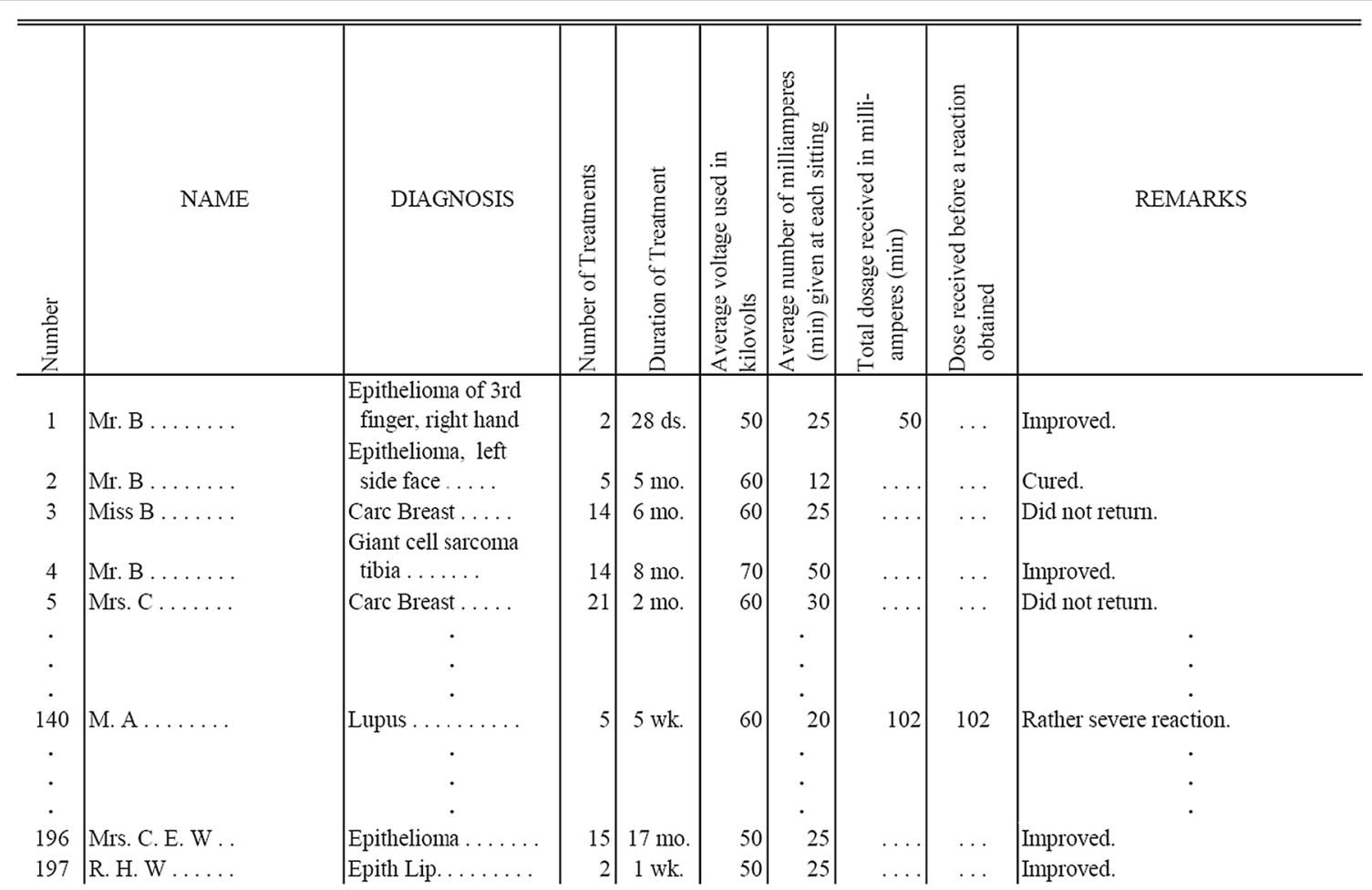

Fig. 3 Excerpt of an example de-identified published database from 1914, "Some Experiments in Standardization of Dosage" [33]. Although precision is limited since this table pre-dates the definition of the rad by 4 decades [35] and was long before any of the modern grading systems [4], nevertheless the sharing of fractionation, multiple parameters of dose, and outcome per patient as still recommended by HyTEC and QUANTEC $[10-12,32]$ is truly remarkable, since this dataset of 197 cases is from more than 100 years ago 
$1 / 3,2 / 3$ and $3 / 3$ organ volume, with the probability of $5 \%$ (TD 5/5) or $50 \%$ (TD 50/5) risks of complications within a 5-year follow-up. The original paper did emphasize the need for more research and available data. Two decades later the ensuing accumulated published data was consolidated into QUANTEC [36] which was much more accurate owing to the growing body of cooperative trials and institutional studies. However, the improved accuracy of QUANTEC also came with increased complexity and varied format of the limits, which is difficult to use in day to day clinical work. The goal of the DVH Risk Map [13] is to balance the convenience of a unified framework of dose tolerance limits in low-risk and high-risk categories, with the accuracy of dose-response modeling from all the emerging published clinical data, particularly in the setting of hypofractionated SBRT.

Brachial plexus dose tolerance for conventional fractionation has been studied [5, 37, 38] and contouring guidelines are available $[2,39,40]$. The Emami limit for brachial plexus of EQD2 $=60$ Gy [5] corresponds to 26 Gy in 3 fractions, which is remarkably the same dose limit as recommended in the Indiana study [1]. However, the paradigm has transformed from allowing $100 \%$ organ exposure at that dose in conventional fractionation [5], now all the way down to the $0 \%$ volume at the same dose for SBRT $[1,41]$.

About one third of the combined dataset had Dmax values in excess of 10 Gy per fraction, where the LQ model has been questioned [16]. For this reason the Karolinska authors compared LQ to USC, and found no major difference for this data [2]. The Indiana dataset was published in terms of physical dose, which avoids questions regarding BED models, but is itself a major limitation of the pooled model since the fractionation was not reported per patient.

Gender, age, histology, number and size of tumors, dose of SBRT, number of fractions, and time to brachial plexopathy from SBRT varied but were reasonably similar across studies as may be seen in Table 2. However, neither study provided these values per patient, therefore no multivariate analyses or subgroups of dose-response models could be performed. The median length of patient follow-up was more than twice as long in the Karolinska study (30 vs 13 months), but at least the median followup in the Indiana University study was longer than the median onset of brachial plexopathy in either study (7 and 5.8 months). Both studies included some patients with less follow-up time than the latest reported complication in either study, so it is highly likely that a longer follow-up period would reveal at least somewhat higher percentage of complications in either study.

Limitations of both studies include data based on a small cohort of patients with limited follow-up. These data may not reflect the full incidence of toxicity after SBRT because many patients might not survive long enough for toxicity to develop or may be lost to followup for a variety of reasons. Another limitation is the usage of re-irradiation for some of the Karolinska cases, although this only caused one of the complications, so insufficient data were available to construct a model that could account for re-irradiation tolerance. The Karolinska authors reported distance and overlap of the brachial plexus to the tumor, but the Indiana University authors did not, so this factor was not included in the pooled analysis. Differences in grading of complications was acknowledged, which may contribute to inaccurate causal analysis. Half of the complications were grade 2, and only one potentially grade 4 paresis was reported in each of the two studies. However, the studies did not indicate the specific grade for each Dmax value of the whole dataset, so separate models for each grade cannot be created, as was done in a brain dose tolerance study [42]. Furthermore, as noted in Table 1, the grading scales vary especially for the higher-grade events. A risk of $10 \%$ is higher than ideal for brachial plexus, but until the grade of each patient is reported in a consistent scale, clinicians must use their own judgement when interpreting the results.

\section{Conclusions}

For lung cancers near the apical region, brachial plexopathy is a major concern for high-dose radiation therapy. Based on our analysis of published data, the risk of grade 2 or higher brachial plexus toxicity after SBRT is approximately $5 \%, 10 \%$, and $50 \%$ at $13.7,26$, and 70 Gy, respectively, in 3-4 fractions, but the risk of grade 3 or 4 toxicity remains unknown. This paper is not intended to be a final answer, but rather an appreciation of recent efforts and a plea for more data: it is commendable that the Indiana and Karolinska authors published the data that enabled this pooled model, as recommended by QUANTEC and HyTEC. When more institutions join the QUANTEC and HyTEC methodology of reporting sufficient details to enable data pooling, our field will finally reach an improved understanding of human dose tolerance.

\section{Appendix}

See Figs. 4, 5 and Table 3. 


\section{Constructing The Emami Paper \\ Parallel Example: Kidney Serial Example: Brachial Plexus}

\section{Comparing Parallel and Serial Structures}

Kidney (Parallel)

More than double the dose is tolerable to small volume vs large volume (5000 vs 2300 cGy)

\section{Brachial Plexus (Serial)}

Dose tolerance is similar for small and large volume

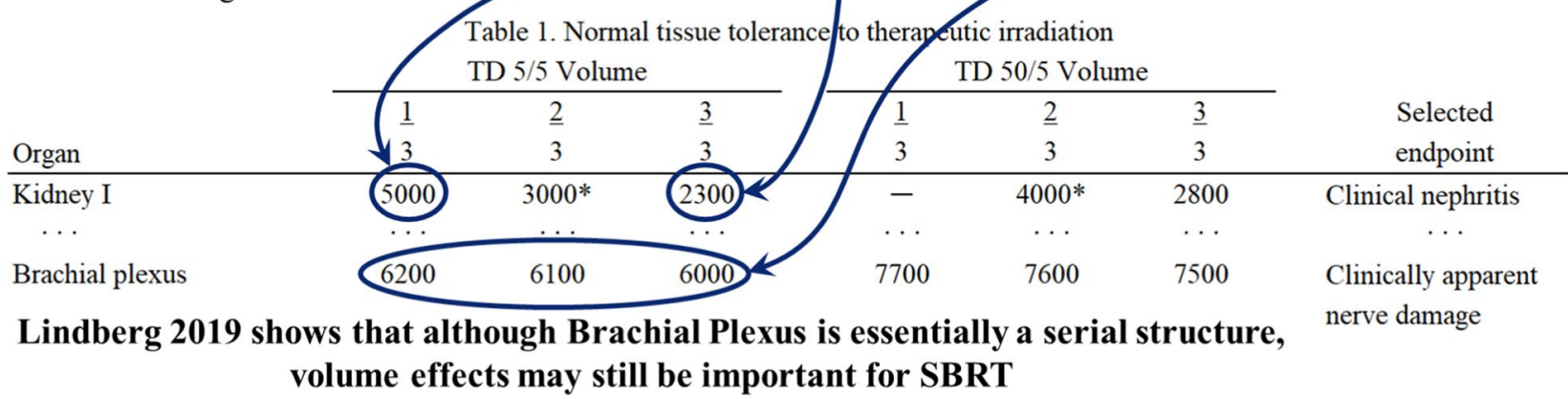

Fig. 4 Emami paper [5] examples from expert opinion and Burman [6] models. Arrows depict how the 5\% risk levels were interpolated from the Burman [6] model for the Emami [5] table of dose tolerance. Dots on the graph depict the TD 5/5 and TD 50/5 tolerance doses, which correspond to the values in the table. Kidney is a parallel structure so it is intuitive that the $5 \%$ risk level for $1 / 3$ and $3 / 3$ volumes were very different, whereas brachial plexus is predominantly a serial structure, so the $5 \%$ risk levels were fairly similar for conventional fractionation regardless of volume. However, Table 3 of the Karolinska study [2] shows a 50\% reduction in tolerance of brachial plexus D3cc as compared to the maximum point dose (Dmax), therefore volume effects may be more important for SBRT. In the Emami paper [5], for both kidney and brachial plexus the TD5/5 and TD50/5 limits were in close agreement with the models. However, for other structures such as Bladder there was more reliance on expert opinion, as can be observed by the location of the TD 5/5 and TD 50/5 dots in the Burman paper [6], in relation to the modeled curves

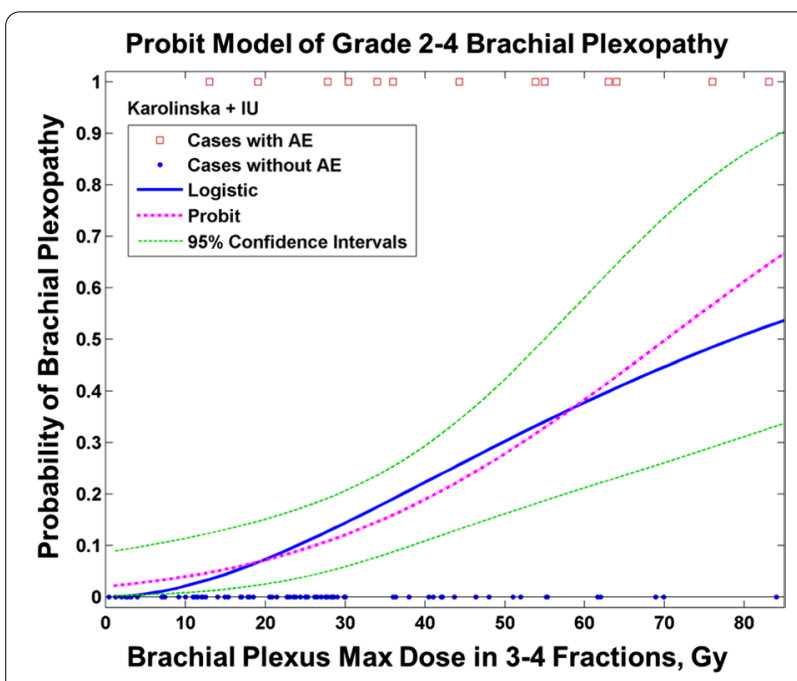

Fig. 5 Comparison of logistic [74] and probit [17] in Schultheiss et al. [75] showed that for some datasets these two models may differ by less than $1 \%$ over their entire range. For this dataset as shown above, the two models differ by no more than $\pm 1.6 \%$ from their average, up to $60 \mathrm{~Gy}$ in 3-4 fractions, but diverge at doses above that where the data is sparse. Abbreviations IUIndiana University, AEadverse event (brachial plexopathy) 


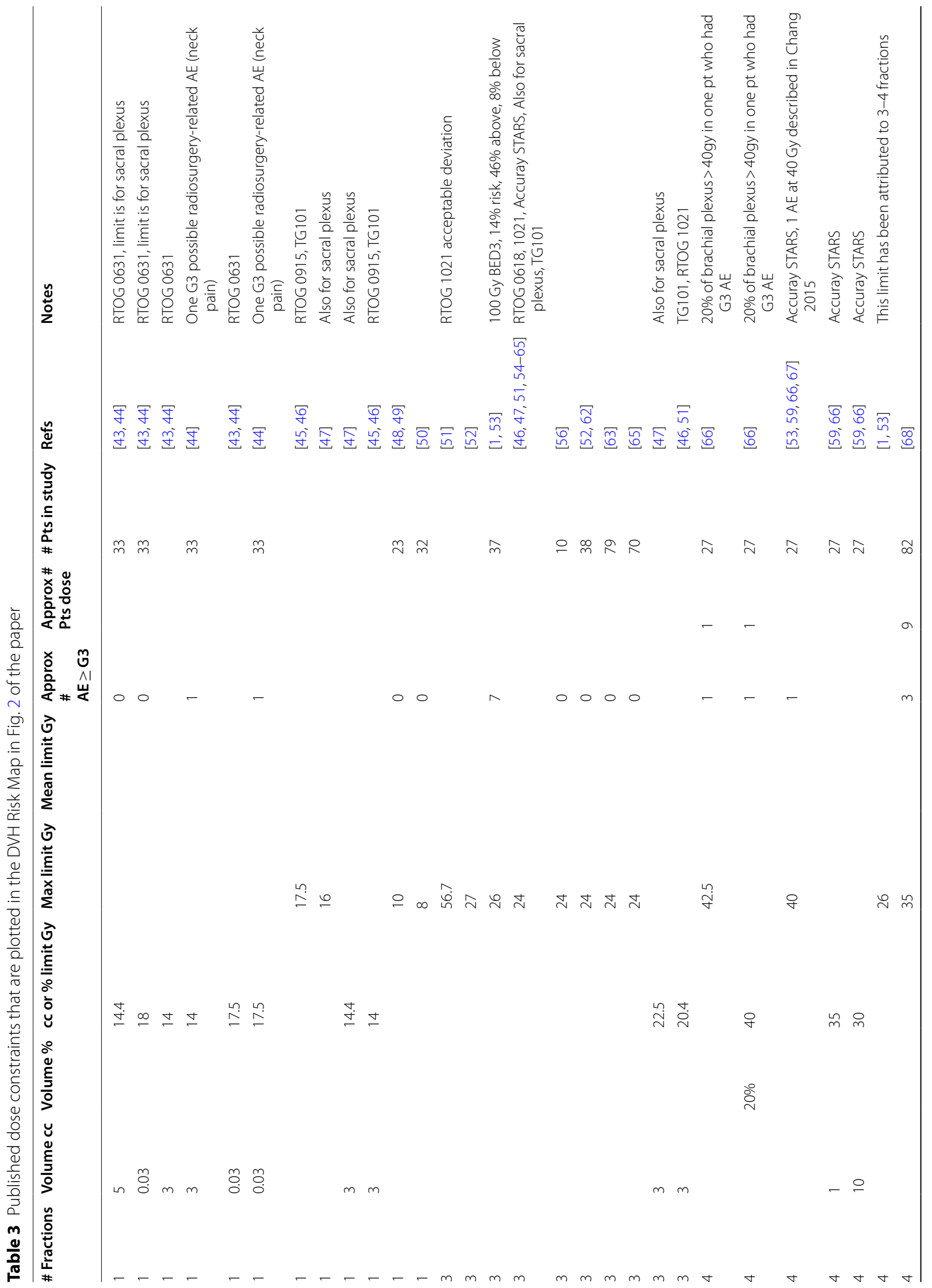




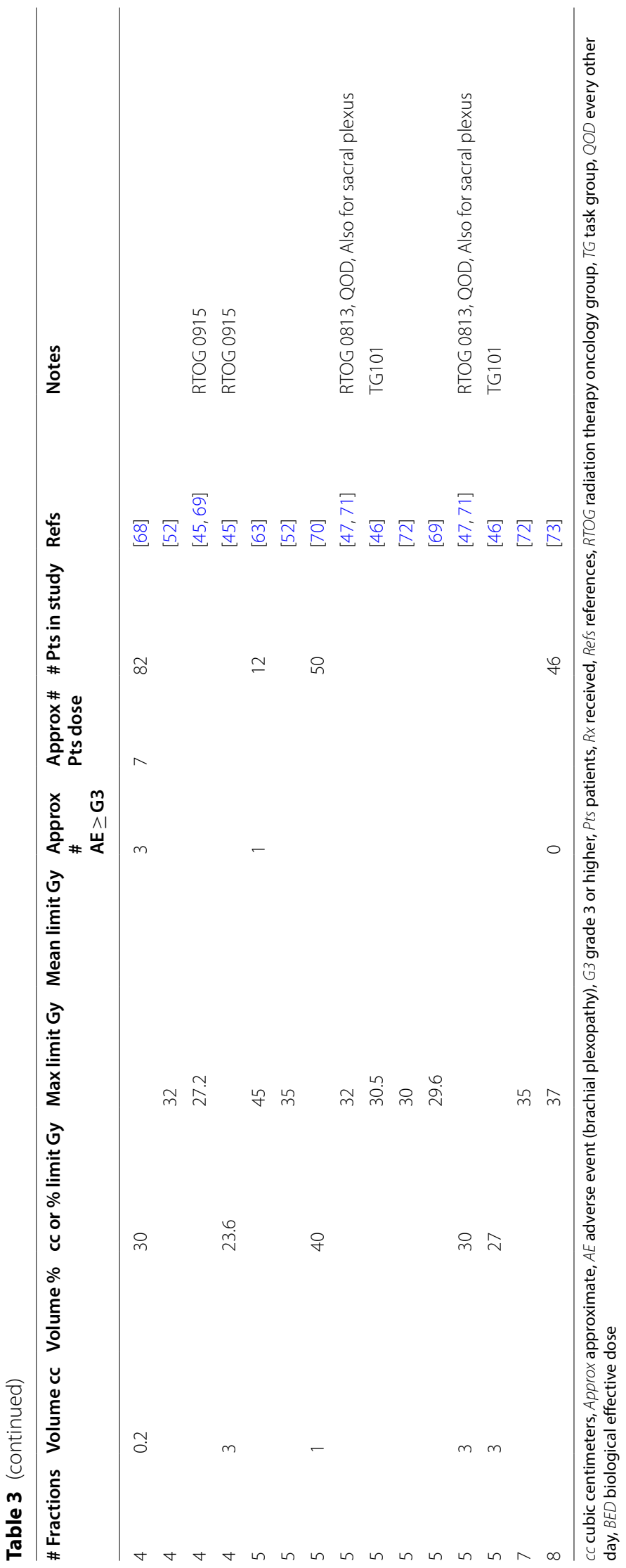


The following form of the probit model [17] was used in the manuscript:

$$
\text { NTCPprobit }=\frac{1}{\sqrt{2 \pi}} \int_{-\infty}^{t} e^{-x^{2} / 2} d x
$$

where $T D_{50}$ is the $50 \%$ risk level, $t=\left(D_{\max }-T D_{50}\right) /\left(m \times T D_{50}\right)$, and $m$ is the normalized slope.

The following form of the logistic model [74] was used in Fig. 5 for comparison:

$$
\text { NTCPlogistic }=1 /\left(1+\left(T D_{50} / D_{\max }\right)^{\wedge}\left(4 * g_{50}\right)\right),(2)
$$

where $T D_{50}$ is the $50 \%$ risk level and $g_{50}$ is the slope parameter.

\section{Acknowledgements}

The authors would like to thank Dr. Paula Lim, MD for working on the manuscript.

\section{Authors' contributions}

All authors contributed to the study concept, drafting and editing the manuscript, and approved the final version for publication. IK, SB, PL, SD, and JG performed the literature review. RJG analyzed the data and created the doseresponse model. IK, SB, PL and SD created the first 10 revisions of the paper. EJK, RAR, KMF, RJG, CJS, JG, BE, AM provided initial clinical input after the 10th revision. $A M$, and $B E$ are the senior authors of the work and made major edits especially toward completion of the work. All authors read and approved the final manuscript.
\end{abstract}

\section{Funding}

None.

\section{Availability of data and materials}

The datasets generated during and/or analysed during the current study are available in the published literature.

\section{Declarations}

\section{Ethics approval and consent to participates}

Not applicable, since data was existent in the literature.

\section{Consent for publication}

Not applicable, since the manuscript does not contain data from any individual person.

\section{Competing interests}

IK, SB, SD, EJK, RAR, KMF, RJG, CJS, BE, AM: None. JG: Grants from Accuray, grants from NovoCure, outside the submitted work; In addition, Dr. Grimm has a patent DVH Evaluator issued.

\footnotetext{
Author details

'Department of Psychiatry, Mount Sinai St. Luke's Hospital, New York, NY, USA. ${ }^{2}$ Department of Pediatric Nephrology, Weill Cornell Medicine, New York, NY, USA. ${ }^{3}$ Sackler School of Medicine, Tel Aviv University, New York, NY, USA. ${ }^{4}$ Department of Radiation Oncology, Geisinger Cancer Institute, $100 \mathrm{~N}$ Academy Ave, Danville, PA 17822, USA. 5 Department of Radiation Oncology, Thomas Jefferson Hospital, Philadelphia, PA, USA. ${ }^{6}$ Department of Medical Imaging and Radiation Sciences, Thomas Jefferson University, Philadelphia, PA, USA. ${ }^{7}$ Department of Radiation Oncology, Loyola University Medical Center, Chicago, IL, USA.
}

Received: 23 October 2020 Accepted: 19 May 2021 Published online: 07 June 2021

\section{References}

1. Forquer JA, Fakiris AJ, Timmerman RD, Lo SS, Perkins SM, McGarry RC, Johnstone PA. Brachial plexopathy from stereotactic body radiotherapy in early-stage NSCLC: dose-limiting toxicity in apical tumor sites. Radiother Oncol. 2009;93(3):408-13

2. Lindberg K, Grozman V, Lindberg S, Onjukka E, Lax I, Lewensohn R, Wersäll P. Radiation-induced brachial plexus toxicity after SBRT of apically located lung lesions. Acta Oncol. 2019;58(8):1178-86.

3. Fathers E, Thrush D, Huson SM, Norman A. Radiation-induced brachial plexopathy in women treated for carcinoma of the breast. Clin Rehabil. 2002;16(2):160-5. https://doi.org/10.1191/0269215502cr470oa.

4. National Cancer Institute. Common Terminology Criteria for Adverse Events v5.0. November 27, 2017. Accessed https:/ctep.cancer.gov/proto colDevelopment/electronic_applications/ctc.htm.

5. Emami B, Lyman J, Brown A, Coia L, Goitein M, Munzenrider JE, Shank B, Solin LJ, Wesson M. Tolerance of normal tissue to therapeutic irradiation. Int J Radiat Oncol Biol Phys. 1991;21(1):109-22.

6. Burman C, Kutcher GJ, Emami B, Goitein M. Fitting of normal tissue tolerance data to an analytic function. Int J Radiat Oncol Biol Phys. 1991;21(1):123-35.

7. Lax I, Blomgren H, Näslund I, Svanström R. Stereotactic radiotherapy of malignancies in the abdomen. Methodol Asp Acta Oncol. 1994;33(6):677-83.

8. Lawrence TS, Ten Haken RK, Kessler ML, Robertson JM, Lyman JT, Lavigne ML, Brown MB, DuRoss DJ, Andrews JC, Ensminger WD, et al. The use of 3-D dose volume analysis to predict radiation hepatitis. Int J Radiat Oncol Biol Phys. 1992;23(4):781-8.

9. Timmerman R, Papiez L, McGarry R, Likes L, DesRosiers C, Frost S, Williams M. Extracranial stereotactic radioablation: results of a phase I study in medically inoperable stage I non-small cell lung cancer. Chest. 2003;124(5):1946-55.

10. Deasy JO, Bentzen SM, Jackson A, Ten Haken RK, Yorke ED, Constine LS, Sharma A, Marks LB. Improving normal tissue complication probability models: the need to adopt a "data-pooling" culture. Int J Radiat Oncol Biol Phys. 2010;76(3 Suppl):S151-4.

11. Jackson A, Marks LB, Bentzen SM, Eisbruch A, Yorke ED, Ten Haken RK, Constine LS, Deasy JO. The lessons of QUANTEC: recommendations for reporting and gathering data on dose-volume dependencies of treatment outcome. Int J Radiat Oncol Biol Phys. 2010;76(3 Suppl):S155-60.

12. Sahgal A, Chang JH, Ma L, Marks LB, Milano MT, Medin P, Niemierko A, Soltys SG, Tomé WA, Wong CS, Yorke E, Grimm J, Jackson J. Spinal cord dose tolerance to stereotactic body radiotherapy. Int J Radiat Oncol Biol Phys. 2021;110(1):124-36.

13. Asbell SO, Grimm J, Xue J, Chew MS, LaCouture TL. Introduction and clinical overview of the DVH Risk Map. Semin Radiat Oncol. 2016;26(2):89-96.

14. Fowler JF, Stern BE. Dose-rate factors in integral dose estimations [letter]. Br J Radiol. 1958;31:316.

15. Fowler JF. 21 years of biologically effective dose. Br J Radiol. 2010;83(991):554-68.

16. Park C, Papiez L, Zhang S, Story M, Timmerman RD. Universal survival curve and single fraction equivalent dose: useful tools in understanding potency of ablative radiotherapy. Int J Radiat Oncol Biol Phys. 2008;70(3):847-52.

17. Herbert D. The assessment of the clinical significance of non-compliance with prescribed schedules of irradiation. Int J Radiat Oncol Biol Phys. 1977;2(7-8):763-72.

18. Jackson A, Ten Haken RK, Robertson JM, Kessler ML, Kutcher GJ, Lawrence TS. Analysis of clinical complication data for radiation hepatitis using a parallel architecture model. Int J Radiat Oncol Biol Phys. 1995;31(4):883-91.

19. Cox DR, Snell EJ. Analysis of binary data. 2nd ed. London: CRC; 1989.

20. Levegrün S, Jackson A, Zelefsky MJ, Skwarchuk MW, Venkatraman ES, Schlegel W, Fuks Z, Leibel SA, Ling CC. Fitting tumor control probability models to biopsy outcome after three-dimensional conformal radiation therapy of prostate cancer: pitfalls in deducing radiobiologic parameters for tumors from clinical data. Int J Radiat Oncol Biol Phys. 2001;51:1064-80

21. Cancer Therapy Evaluation Program, Common Terminology Criteria for Adverse Events, Version3.0, DCTD, NCl, NIH, DHHS, March 31, 2003. http:// ctep.cancer.gov. Publish date 9 Aug 2006. 
22. Cancer Therapy Evaluation Program, Common Terminology Criteria for Adverse Events, Version4 .0, DCTD, NCI, NIH, DHHS, December 23, 2009. http://ctep.cancer.gov. Publish date 28 May 2009.

23. LENT SOMA scales for all anatomic sites. Int J Radiat Oncol Biol Phys. 1995;31:1049-1091.

24. Fehlauer $F$, Tribius $S$, Holler $U$, et al. Long-term radiation sequelae after breast-conserving therapy in women with early-stage breast cancer: an observational study using the LENT-SOMA scoring system. Int J Radiat Oncol Biol Phys. 2003:55:651-8.

25. Fisher RA. On the interpretation of $\times 2$ from contingency tables, and the calculation of P. J R Stat Soc. 1922;85:87.

26. Cox BW, Jackson A, Hunt M, Bilsky M, Yamada Y. Esophageal toxicity from high-dose, single-fraction paraspinal stereotactic radiosurgery. Int J Radiat Oncol Biol Phys. 2012;83(5):e661-7.

27. Kimsey F, McKay J, Gefter J, Milano MT, Moiseenko V, Grimm J, Berg R. Dose-response model for chest wall tolerance of stereotactic body radiation therapy. Semin Radiat Oncol. 2016;26(2):129-34.

28. Xue J, Kubicek G, Patel A, Goldsmith B, Asbell SO, LaCouture TA. Validity of current stereotactic body radiation therapy dose constraints for aorta and major vessels. Semin Radiat Oncol. 2016;26(2):135-9.

29. Goldsmith C, Price P, Cross T, Loughlin S, Cowley I, Plowman N. Dosevolume histogram analysis of stereotactic body radiotherapy treatment of pancreatic cancer: a focus on duodenal dose constraints. Semin Radiat Oncol. 2016;26(2):149-56.

30. Kondziolka D. Current and novel practice of stereotactic radiosurgery. J Neurosurg. 2019;130(6):1789-98.

31. Depp JG. Personal Communication, Founding President and CEO, Accuray Incorporated. Accessed http://quantum.site.nfoservers.com/ Joe/.

32. Mahadevan A, Moningi S, Grimm J, Li XA, Forster KM, Palta M, Prior P, Goodman KA, Narang A, Heron DE, Urbanic Lo SS, J, Herman JM. Maximizing Tumor Control and limiting complications with SBRT for Pancreatic Cancer. Int J Radiat Oncol Biol Phys. 2021;110(1):206-16.

33. Holmes G. Some experiments in standardization of dosage for Roentgen therapeutics. Am J Röentgenol. 1914;1:298-302.

34. Quimby EH, Pack GT. The skin erythema for combinations of gamma and Roentgen rays. Radiology 1929;13:306 [Read by Mrs. Edith H. Quimby before the Radiological Society of North America at the fourteenth annual meeting, at Chicago, 3-7 Dec 1928].

35. Taylor LS. History of the international commission on radiological units and measurements (ICRU). Health Phys. 1958;1(3):306-14.

36. Marks LB, Yorke ED, Jackson A, Ten Haken RK, Constine LS, Eisbruch A, Bentzen SM, Nam J, Deasy JO. Use of normal tissue complication probability models in the clinic. Int J Radiat Oncol Biol Phys. 2010;76(3 Suppl):S10-9.

37. Svensson H, Westling P, Larsson LG. Radiation-induced lesions of the brachial plexus correlated to the dose-time-fraction schedule. Acta Radiol Ther Phys Biol. 1975;14(3):228-38.

38. Yan $\mathrm{M}$, Kong W, Kerr A, Brundage $\mathrm{M}$. The radiation dose tolerance of the brachial plexus: A systematic review and meta-analysis. Clin Transl Radiat Oncol. 2019;18:23-31.

39. Kong FM, Ritter T, Quint DJ, Senan S, Gaspar LE, Komaki RU, Hurkmans CW, Timmerman R, Bezjak A, Bradley JD, Movsas B, Marsh L, Okunieff P, Choy H, Curran WJ Jr. Consideration of dose limits for organs at risk of thoracic radiotherapy: atlas for lung, proximal bronchial tree, esophagus, spinal cord, ribs, and brachial plexus. Int J Radiat Oncol Biol Phys. 2011;81(5):1442-57.

40. Li CH, Wu VW, Chiu G. A dosimetric evaluation on applying RTOG-based and CT/MRI-based delineation methods to brachial plexus in radiotherapy of nasopharyngeal carcinoma treated with helical tomotherapy. Br J Radiol. 2019;92(1102):20170881.

41. Ma TM, Emami B, Grimm J, Xue J, Asbell SO, Kubicek GJ, Lanciano R, Welsh JS, Peng L, Gui C, Das IJ, Goldman HW, Brady LW, Redmond KJ, Kleinberg $L R$. Volume effects in radiosurgical spinal cord dose tolerance: how small is too small? J Radiat Oncol. 2019;8:53-61.

42. Peng L, Grimm J, Gui C, Shen CJ, Redmond KJ, Sloan L, Hazell S, Moore JA, Huang E, Spoleti N, Laub W, Quon H, Bettegowda C, Lim M, Kleinberg LR. Updated risk models demonstrate low risk of symptomatic radionecrosis following stereotactic radiosurgery for brain metastases in the modern era. Surg Neurol Int. 2019;10:32.
43. Ryu S, Gerszten P, Yin F, Timmerman R, Dicker A, Movsas B, Wang M. Phase II/III study of image-guided radiosurgery/SBRT for localized spine metastasis. Radiation Therapy Oncology Group 0631. Accessed http://www. rtog.org.

44. Ryu S, Pugh SL, Gerszten PC, Yin FF, Timmerman RD, Hitchcock YJ, Movsas B, Kanner AA, Berk LB, Followill DS, Kachnic LA. RTOG 0631 phase 2/3 study of image guided stereotactic radiosurgery for localized (1-3) spine metastases: phase 2 results. Pract Radiat Oncol. 2014;4(2):76-81.

45. Videtic G, Singh A, Chang J, Le Q, Parker W, Olivier K, Schild S, Bae K. A randomized phase II study comparing 2 stereotactic body radiation therapy (SBRT) schedules for medically inoperable patients with stage I peripheral non-small cell lung cancer. Radiation Therapy Oncology Group 0915. Accessed at http://www.rtog.org.

46. Benedict S, Yenice KM, Followill D, Galvin JM, Hinson W, Kavanagh B, Keall P, Lovelock M, Meeks S, Papiez L, Purdie T, Sadagopan R, Schell MC, Salter B, Schlesinger DJ, Shiu AS, Solberg T, Song DY, Stieber V, Timmerman R, Tomé WA, Verellen D, Wang L, Yin FF. Stereotactic body radiation therapy: the report of AAPM Task Group 101. Med Phys. 2010;37(8):4078-101.

47. Timmerman RD. An overview of hypofractionation and introduction to this issue of seminars in radiation oncology. Semin Radiat Oncol. 2008;18:215-22.

48. Whyte RI, Crownover R, Murphy MJ, Martin DP, Rice TW, DeCamp MM Jr, Rodebaugh R, Weinhous MS, Le QT. Stereotactic radiosurgery for lung tumors: preliminary report of a phase I trial. Ann Thorac Surg. 2003;75(4):1097-101.

49. Le QT, Loo BW, Ho A, Cotrutz C, Koong AC, Wakelee H, Kee ST, Constantinescu D, Whyte RI, Donington J. Results of a phase I dose-escalation study using single-fraction stereotactic radiotherapy for lung tumors. J Thorac Oncol. 2006;1 (8):802-9.

50. Pennathur A, Luketich JD, Burton S, Abbas G, Heron DE, Fernando HC, Gooding WE, Ozhasoglu C, Ireland J, Landreneau RJ, Christie NA. Stereotactic radiosurgery for the treatment of lung neoplasm: initial experience. Ann Thorac Surg. 2007;83(5):1820-4 (discussion 1824-5).

51. Fernando H, Meyers B, Timmerman R, et al. RTOG 1021 A randomized phase III study of sublobar resection (+/- brachytherapy) versus stereotactic body radiation therapy in high risk patients with stage I non-small cell lung cancer (NSCLC).

52. Mutter RW, Liu F, Abreu A, Yorke E, Jackson A, Rosenzweig KE. Dosevolume parameters predict for the development of chest wall pain after stereotactic body radiation for lung cancer. Int J Radiat Oncol Biol Phys. 2012;82(5):1783-90.

53. Milano MT, Constine LS, Okunieff P. Normal tissue toxicity after small field hypofractionated stereotactic body radiation. Radiat Oncol. 2008;3:36.

54. Timmerman RD, Pass H, Galvin J, Edelman MJ, Gore E, Kong FM. A phase II trial of stereotactic body radiation therapy (SBRT) in the treatment of patients with operable stage I/II non-small cell lung cancer. Radiation Therapy Oncology Group 0618. Accessed http://www.rtog.org.

55. Chang BK, Timmerman RD. Stereotactic body radiation therapy: a comprehensive review. Am J Clin Oncol. 2007;30:637-44.

56. Sinha B, McGarry RC. Stereotactic body radiotherapy for bilateral primary lung cancers: the Indiana University experience. Int J Radiat Oncol Biol Phys. 2006;66:1120-4.

57. Mould RF, Schulz RA, Bucholz RD, Gagnon GJ, Gerszten PC, Kresl JJ, Levendag PC, Schulz RA, et al. Robotic Radiosurgery, vol. 1. Sunnyvale: Cyberknife Society Press; 2005.

58. Urschel HC, Kresl JJ, Luketich JD, Papiez L, Timmerman RD, Schulz RA. Treating tumors that move with respiration. Berlin: Springer; 2007.

59. Roth J, Chang J, Komaki R, KresI J. International randomized study to compare CyberKnifeR stereotactic radiotherapy with surgical resection in stage I non-small cell lung cancer (STARS). Accessed http://clinicaltrials. gov.

60. Dunlap NE, Cai J, Biedermann GB, Yang W, Benedict SH, Sheng K, Schefter $T E$, Kavanagh BD, Larner JM. Chest wall volume receiving $>30$ Gy predicts risk of severe pain and/or rib fracture after lung stereotactic body radiotherapy. Int J Radiat Oncol Biol Phys. 2010;76(3):796-801.

61. Schefter T, Kavanagh B, Raben D, Kane M, Chen C, Stuhr K, et al. A phase I/ Il trial of Stereotactic body radiation therapy (SBRT) for lung metastases: Initial report of dose escalation and early toxicity. Int J Radiat Oncol Biol Phys. 2006;60:S120-7.

62. Rusthoven KE, Kavanagh BD, Burri SH, Chen C, Cardenes H, Chidel MA, Pugh TJ, Kane M, Gaspar LE, Schefter TE. Multi-institutional phase I/II trial 
of stereotactic body radiation therapy for lung metastases. J Clin Oncol. 2009;27(10):1579-84.

63. Bradley JD, El Naqa I, Drzymala RE, Trovo M, Jones G, Denning MD. Stereotactic body radiation therapy for early-stage non-small-cell lung cancer: the pattern of failure is distant. Int J Radiat Oncol Biol Phys. 2010;77(4):1146-50.

64. Wulf J, Hadinger U, Oppitz U, Thiele W, Ness-Dourdoumas R, Flentje M. Stereotactic radiotherapy of targets in the lung and liver. Strahlenther Onkol. 2001;177(645):55

65. van der Voort van Zyp NC, Prévost JB, Hoogeman MS, Praag J, van der Holt B, Levendag PC, van Klaveren RJ, Pattynama P, Nuyttens JJ. Stereotactic radiotherapy with real-time tumor tracking for non-small cell lung cancer: clinical outcome. Radiother Oncol. 2009;91(3):296-300.

66. Chang JY, Balter PA, Dong L, Yang Q, Liao Z, Jeter M, Bucci MK, McAleer MF, Mehran RJ, Roth JA, Komaki R. Stereotactic body radiation therapy in centrally and superiorly located stage I or isolated recurrent non-smallcell lung cancer. Int J Radiat Oncol Biol Phys. 2008;72:967-71.

67. Chang JY, Bezjak A, Mornex F, IASLC Advanced Radiation Technology Committee. Stereotactic ablative radiotherapy for centrally located early stage non-small-cell lung cancer: what we have learned. J Thorac Oncol. 2015;10(4):577-85.

68. Chang JY, Li QQ, Xu QY, Allen PK, Rebueno N, Gomez DR, Balter P, Komaki R, Mehran R, Swisher SG, Roth JA. Stereotactic ablative radiation therapy for centrally located early stage or isolated parenchymal recurrences of non-small cell lung cancer: how to fly in a "no fly zone." Int J Radiat Oncol Biol Phys. 2014;88(5):1120-8.

69. Mangona VS, Aneese AM, Marina O, Hymas RV, lonascu D, Robertson JM, Gallardo LJ, Grills IS. Toxicity after central versus peripheral lung stereotactic body radiation therapy: a propensity score matched-pair analysis. Int J Radiat Oncol Biol Phys. 2015;91(1):124-32.
70. Takeda A, Kunieda E, Sanuki N, Ohashi T, Oku Y, Sudo Y, Iwashita H, Ooka Y, Aoki Y, Shigematsu N, Kubo A. Dose distribution analysis in stereotactic body radiotherapy using dynamic conformal multiple arc therapy. Int J Radiat Oncol Biol Phys. 2009;74(2):363-9.

71. Bezhak A, Bradley J, Gaspar L, Timmerman R, Papiez L, Gore E, Kong F, Bae K, Normolle, D. Seamless phase I/II study of stereotactic lung radiotherapy (SBRT) for early stage, centrally located, non-small cell lung cancer (NSCLC) in medically inoperable patients. Radiation Therapy Oncology Group 0813. Accessed http://www.rtog.org.

72. Nuyttens JJ, Moiseenko V, McLaughlin M, Jain S, Herbert S, Grimm J. Esophageal dose tolerance in patients treated with stereotactic body radiation therapy. Semin Radiat Oncol. 2016;26(2):120-8.

73. Onimaru R, Shirato H, Shimizu S, Kitamura K, Xu B, Fukumoto S, Chang TC, Fujita K, Oita M, Miyasaka K, Nishimura M, Dosaka-Akita H. Tolerance of organs at risk in small-volume, hypofractionated, image-guided radiotherapy for primary and metastatic lung cancers. Int J Radiat Oncol Biol Phys. 2003;56(1):126-35.

74. Fischer DB, Fischer JJ. Dose response relationships in radiotherapy: applications of logistic regression models. Int J Radiat Oncol Biol Phys. 1977;2(7-8):773-81.

75. Schultheiss TE, Orton CG, Peck RA. Models in radiotherapy: volume effects. Med Phys. 1983;10(4):410-5.

\section{Publisher's Note}

Springer Nature remains neutral with regard to jurisdictional claims in published maps and institutional affiliations.
Ready to submit your research? Choose BMC and benefit from:

- fast, convenient online submission

- thorough peer review by experienced researchers in your field

- rapid publication on acceptance

- support for research data, including large and complex data types

- gold Open Access which fosters wider collaboration and increased citations

- maximum visibility for your research: over $100 \mathrm{M}$ website views per year

At BMC, research is always in progress.

Learn more biomedcentral.com/submissions 